\title{
ORDENAMENTO JURÍDICO PARA A PROTEÇÃO DO PATRIMÔNIO NATURAL NO BRASIL
}

\author{
Wagner Costa Ribeiro \\ Prof. do Depto. de Geografia e do Procam/USP.
}

Silvia Helena Zanirato

Profa. do Depto. de História/UEM. Pesquisa financiada pelo CNPq.

\section{Resumo}

Proteção ambiental envolve riqueza potencial e desenvolvimento econômico sobre novas bases. Para tratar da conservação ambiental no B rasil, organizamos este texto que se inicia com a proteção natural na escala internacional, aborda as normativas e ações que contribuíram para a salvaguarda do patrimônio natural brasil eiro na escala federal e, por fim, apresenta al gumas experiências estaduais.

\section{Pallavras-chaves}

Patrimônio natural • legislação ambiental • políticas públicas.

\section{Abstract}

Environmental protection involves potential wealth and economic development on new bases. To discuss the environmental conservation in Brazil we organize this text, which begins with the natural protection in the international scale, presents regulations and actions that contributed to the protection of Brazilian natural heritage in federal approach, and, finally, some experiences in Brazilian states.

\section{Keywords}

Natural heritage $\bullet$ environmental legislation $\bullet$ public policies. 
Proteger a natureza atende a diversos pontos de vista. Por isso, a definição de uma área natural protegida decorre de um processo longo que passa por diversas etapas, todas embasadas em valores que se expressam na esfera da cultura.

Podemos dizer que há uma relação entre patrimônio e herança. Segundo a acepção da Organização das Nações Unidas para a Educação, a Ciência e a Cultura - Unesco, o patrimônio é um legado que recebemos do passado, que vivemos no presente e que transmitimos às gerações futuras; uma fonte insubstituível de vida e inspiração, nosso ponto de referência, nossa identidade (Unesco, 2005).

$\mathrm{O}$ patrimônio cultural refere-se às manifestações materiais e imateriais, tangíveis e intangíveis que afirmam e promovem a identidade cultural de um povo e que são transmitidas de geração a geração. Uma definição como esta implica em compreender que os seres humanos são produtores de cultura e que a identidade cultural de um povo é forjada no meio em que ele vive. Por isso, o ambiente também é patrimônio.

O patrimônio natural tem sido entendido como as formações físicas, biológicas e geológicas excepcionais, hábitats de espécies animais e vegetais ameaçadas e zonas que tenham valor científico, de conservação ou estético (Unesco, 2005).

Tal sentido também traduz outra concepção a respeito da natureza. Se, durante séculos, esta foi considerada hostil aos propósitos civilizatórios, algo a ser domado pela espécie humana, uma vez que era admitida como antagônica à cultura, a degradação ambiental ocorrida ao longo do século XX fez emergir outro olhar. Já não se podia consumi-la infinitamente; havia que preservar o ambiente natural para buscar qualidade de vida no presente e no futuro, além de procurar manter áreas naturais protegidas com fins de contemplação, pesquisa científica e desenvolvimento tecnológico.

Nesse contexto, natureza e cultura passaram a ser vistas em conjunto e a salvaguarda de ambas tornou-se objeto das políticas patrimoniais.

Entretanto, a proteção ambiental é mais do que uma exigência romântica para manter ambientes naturais aprazíveis à contemplação. Ela envolve riqueza potencial e desenvolvimento econômico sobre novas bases. Por isso, um país como o Brasil, dotado da maior reserva de informação genética do mundo, deve discutir esse tema de modo a garantir que o legado de milhões de anos de processos naturais não seja dizimado por processos sociais atuais que impeçam o acesso das gerações futuras a esse legado de informações naturais. 
Organizamos este texto para contribuir nesse debate. Ele parte da proteção do patrimônio natural na escala internacional que influenciou e muito as normas jurídicas desenvolvidas e aplicadas no Brasil, tratadas a seguir. Por fim, aponta casos estaduais que criaram a normativa de salvaguarda de parte do patrimônio natural brasileiro.

\section{Proteção do patrimônio natural no âmbito internacional}

Desde os primeiros enunciados a respeito da incorporação da natureza como patrimônio, gradativamente também se constituiu um campo legal que instituiu normas necessárias para sua preservação. O princípio era o de resguardar o que não se pode reconstituir e manter áreas para conhecer a dinâmica natural do planeta. Paralelamente, percebeu-se que a preservação de áreas naturais implicava em ultrapassar o campo de alcance das normas jurídicas dos países, uma vez que os sistemas naturais como a bacia amazônica, por exemplo, ultrapassam os limites dos estados. Além disso, os impactos causados pela degradação do ambiente também não coincidem necessariamente com as fronteiras nacionais. Passou-se a buscar medidas internacionais de proteção e de controle do uso do ambiente natural.

Uma primeira alusão nesse campo pode ser encontrada no Tratado constitutivo da Unesco, de 1945, que em seu preâmbulo fez menção "à existência de um patrimônio universal no âmbito da cultura” (Silva, 2003, p. 34).

A Unesco tornou-se a organização responsável pela proteção do patrimônio cultural em escala mundial. Também promoveu encontros da comunidade internacional para a criação, promoção e divulgação de instrumentos normativos, celebrados por meio de convenções e recomendações destinadas à salvaguarda de elementos significativos da presença humana na Terra. Teve início, a partir de então, uma ordem internacional para a proteção do patrimônio cultural.

Dentre os instrumentos de cooperação elaborados em conjunto pela comunidade internacional encontram-se as recomendações, resoluções e convenções. As recomendações têm um caráter pontual e sugerem medidas sem um valor vinculativo. As resoluções levam os estados-membros à adoção de medidas concretas. Elas, assim como as convenções, constituem o aparato jurídico que normatiza as relações entre países. As convenções são tratados multilaterais aprovados pelos estados; são normas que impõem obrigações recíprocas aos países contratantes e que devem ser ratificadas pelos governos signatários que 
assumem obrigações de executarem suas disposições em seu estrito termo (Silva, 2003, p. 57).

Até 1972, além da responsabilidade de conduzir as discussões no âmbito da cultura, a Unesco também respondia pelo comando das discussões ambientais no interior da ONU. Ao mesmo tempo em que coordenava os encontros internacionais para a preservação do patrimônio cultural, executava programas de educação ambiental e promovia conferências internacionais envolvendo a temática do ambiente.

Uma das primeiras ações da Unesco no que se refere à questão ambiental ocorreu em 1949, por ocasião da realização da Conferência das Nações Unidas para a Conservação e Utilização dos Recursos. O resultado deste encontro foi um diagnóstico da situação ambiental mundial (Ribeiro, 2001, p. 63).

Depois disso, outro evento de destaque foi a conferência realizada em Paris, em 1962, na qual foi aprovada a recomendação relativa à salvaguarda da beleza e do caráter das paisagens e sítios. Neste documento estavam indicadas as medidas para a proteção das paisagens naturais e das transformadas pela espécie humana, sua inclusão no planejamento urbano e regional e a criação de parques e reservas naturais. Além disso, constavam medidas para a proteção legal por zonas e proteção de sítios isolados (Recomendación, 1962). Essas medidas em muito se aproximavam do instrumento legal de preservação e influenciaram a criação de outros tipos de unidades de conservação, como as Áreas de Proteção Ambiental- APAs que temos no Brasil, que não implicam na desapropriação de terras.

Distinguem-se, naquele período, os seguintes elementos para a preservação ambiental: a preocupação com a perda de vida selvagem, em função de sua importância científica; a manutenção de áreas necessárias à vida humana (como elemento regenerador físico e espiritual); e, também, áreas de potencial econômico, detentoras de recursos que possam vir a ser utilizados no futuro. Também se vê expresso pela primeira vez o estímulo à criação de áreas protegidas e a inclusão desta estratégia nos sistemas de planejamento territorial como um princípio norteador de políticas públicas. Não obstante a importância dessas recomendações, elas tiveram apenas um conteúdo normativo, "expressando dificuldades de se estabelecer regras e exigências internacionais" (Scifoni, 2003, p. 83).

Divisa-se, no decorrer dos anos 1960, o crescimento do que pode ser considerado o despertar dos governos com a situação ambiental (Nazo e Mukai, 2003, p. 109). Ao longo dessa década foram elaboradas séries de leis por diversos 
países interessados em tentar controlar a poluição das águas continentais, do mar, do ar e em salvaguardar zonas específicas. É o caso da Carta Européia das Águas, de 1968, que estabeleceu o princípio de que as águas não conhecem fronteiras e, portanto, os cuidados em seu trato precisavam ser supranacionais; ou da Convenção Africana para a Conservação da Natureza e de seus Recursos Naturais, também de 1968, que estendeu aos estados africanos o compromisso para a criação de reservas, regulamentação da caça, da pesca e da proteção a espécies da fauna e da flora (idem, p. 110).

Talvez o maior destaque dentre as preocupações ambientais dessa década possa ser a Conferência Intergovernamental de Especialistas sobre Bases Científicas para o Uso e Conservação Racionais dos Recursos da Biosfera, reunião realizada em Paris, em 1968, quando se discutiram os impactos ambientais causados pela ação humana. Dessa conferência resultou um programa interdisciplinar - $\mathrm{O}$ homem e a biosfera - que reuniu estudiosos dos sistemas naturais para analisarem as conseqüências das demandas econômicas em tais ambientes (Ribeiro, 2003, p. 605-606).

A década seguinte ampliou a inquietação com a problemática ambiental de tal forma que resultou na aprovação da Resolução n 2.749 (XXV) de 1970, pela Assembléia Geral das Nações Unidas sobre os Princípios que Regulam os Fundos Marinhos e Oceânicos e seu Subsolo fora dos Limites da Jurisdição Nacional. Segundo a declaração assinada pelos estados participantes, os fundos oceânicos constituíam um patrimônio comum da humanidade. Sendo assim, seus recursos deveriam ser explorados sob a gestão de uma organização internacional, cuja atuação deveria se pautar "pelos princípios da não apropriação, da utilização pacífica da exploração e exploração da zona e seus recursos no interesse de toda a humanidade e priorizar os países em desenvolvimento, dentro dos propósitos da Carta das Nações Unidas" (Silva, 2003, p. 35).

Isso tudo corrobora a construção de uma ordem ambiental internacional, ou seja, um conjunto de convenções internacionais que busca regular as ações humanas sobre o ambiente em escala internacional (Ribeiro, 2001), na qual a Unesco teve um papel destacado até a década de 1970. Porém, esse cenário se alterou a partir de 1972, quando ela passou a dividir as ações no campo da conservação ambiental com outros organismos multilaterais. Em julho daquele ano, ocorreu em Estocolmo a Conferência sobre o Meio Ambiente Humano, primeira grande conferência convocada pela ONU para tratar de princípios básicos para a proteção ambiental. 
A declaração final da Conferência de Estocolmo pode ser considerada o esteio do atual direito internacional do meio ambiente. Nela ficaram definidos que os estados têm o direito soberano de explorar seus recursos de acordo com sua política ambiental, e a responsabilidade de garantir que sua ação não venha a prejudicar áreas além dos limites de sua jurisdição (Nazo e Mukay, 2003, p. 111). Nos termos da declaração "os recursos naturais da Terra e, especialmente, parcelas representativas dos ecossistemas naturais devem ser preservados em benefício das gerações atuais e futuras". Do mesmo modo, "o homem tem a responsabilidade especial de preservar e administrar judiciosamente o patrimônio representado pela flora e pela fauna silvestres, bem como o seu hábitat" (Declaración, 1972).

Outra decisão da Conferência de Estocolmo foi a criação do Programa das Nações Unidas para o Meio Ambiente (Pnuma), organização multilateral que passou a centralizar as ações ambientais no interior da ONU, bem como o Fundo Mundial para o Meio Ambiente. O Pnuma passou a funcionar em 1973, porém sua sede foi inaugurada em Nairóbi, no Quênia, apenas em 1986.

Por meio do Pnuma, a temática ambiental passou a ser abordada cada vez mais em escala internacional. Ele organizou várias convenções que tratam do ambiente, entre elas a Convenção sobre o Comércio Internacional de Espécies da Flora e Fauna Selvagens em Perigo de Extinção, em 1973; a Convenção sobre Poluição Transfronteiriça de Longo Alcance, em 1979; a Convenção da Basiléia sobre o Controle de Movimentos Transfronteiriços de Resíduos Perigosos e seu Depósito, em 1979; a Convenção de Viena para a Proteção da Camada de Ozônio, em 1985, e o Protocolo de Montreal sobre Substâncias que destroem a Camada de Ozônio, em 1987 (Ribeiro, 2003, p. 608).

Enquanto o Pnuma ganhava corpo institucional, a Unesco organizou a Convenção Relativa à Proteção do Patrimônio Mundial, Cultural e Natural, celebrada em Paris em 1972. Sua convocação se deu em face do reconhecimento da necessidade de proteger os elementos valorados no campo cultural e as áreas naturais. Também influenciou essa reunião internacional a constatação da intensa degradação ambiental gerada pelas transformações da vida social e econômica.

Nessa ocasião a Unesco expressou a compreensão de que a proteção de uma área não poderia se efetuar unicamente em escala nacional, devido à magnitude dos meios necessários para esse procedimento que, não raras vezes, extrapolavam os recursos econômicos, científicos e tecnológicos, dos quais os países que abrigavam os elementos patrimoniais eram detentores. A proteção deveria ser de toda a humanidade. Com essa avaliação, a Unesco elaborava o conceito de 
patrimônio mundial, constituído por criações humanas e expressões de processos naturais de interesse excepcional, por vezes testemunhos únicos que deveriam ser considerados pertencentes não apenas aos estados em que se encontravam, mas a toda a humanidade. Esta deveria se envolver em sua defesa e salvaguarda, de modo a assegurar a sua transmissão às gerações futuras (Convención, 1972).

Ficou então definido, no artigo $1^{\circ}$ da Convenção, que o patrimônio cultural englobava os monumentos, o grupo de edifícios e os lugares dotados de "um valor universal excepcional", do ponto de vista da história, da arte, da ciência, ou do ponto de vista estético, etnológico ou antropológico. Os elementos culturais que se encontrassem dentro desses critérios seriam inscritos na Lista Mundial de Patrimônio da Humanidade.

Segundo o entendimento dos convencionais de 1972, para que uma paisagem cultural fosse inserida na referida lista deveria expressar formas específicas de interação entre a cultura e o meio físico. As paisagens produzidas intencionalmente, como jardins, paisagens que apresentassem provas manifestas da sua dinâmica natural ao longo do tempo e paisagens associativas definidas pela associação de significados simbólicos não imediatamente tangíveis à natureza.

A Unesco também definiu, no artigo $2^{\circ}$, que o patrimônio natural seria composto por bens igualmente dotados de um valor excepcional do ponto de vista estético e/ou científico. Estes bens englobavam os monumentos naturais constituídos por formações físicas e biológicas ou por grupos dessas formações; as formações geológicas e fisiográficas das zonas estritamente delimitadas que constituam o hábitat de espécies animais e vegetais ameaçadas; e os lugares ou as zonas naturais estritamente delimitados, dotados de beleza natural.

Para concretizar os propósitos da proteção foram constituídos o Comitê do Patrimônio Mundial e o Fundo do Patrimônio Mundial. O primeiro, um órgão intergovernamental, constituído por representantes de 21 estados-partes na Convenção, eleitos periodicamente. ${ }^{1}$ Este Comitê ficou responsável por identificar o referido patrimônio e inscrevê-lo na lista mundial; zelar por esses "bens" em conjunto com o estado onde eles se encontram; decidir quais estão em situação de perigo e determinar as condições e os meios apropriados para que um Estado possa aceder ao Fundo do Patrimônio Mundial. Os recursos do Fundo resultam de contribuições obrigatórias e voluntárias dos estados-partes, participação da Unesco, doações de outras agências da ONU, principalmente do

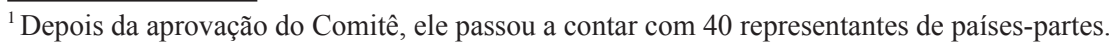


Programa das Nações Unidas para o Desenvolvimento (Pnud) e de organismos públicos e privados, bem como de receitas de manifestações organizadas em prol do Fundo.

Como pode ser percebido, a Convenção definiu que os bens deveriam expressar um valor universal excepcional do ponto de vista da história, da arte, da ciência, da conservação e da beleza natural; um critério vago e difícil de aplicar, segundo Françoise Choay (2001, p. 207).

Certamente, por isso mesmo, em 1977, em suas diretrizes operacionais, a Unesco procurou precisar melhor os critérios que norteariam o significado do que os bens deveriam ser portadores para que pudessem ser merecedores da proteção: valor estético, ecológico e científico. A beleza cênica, como aquela que se expressa nas paisagens notáveis e de extraordinária beleza natural, ou em condição de exceção como o Parque Nacional de Iguaçu, no Brasil e Los Glaciares, na Argentina. A importância ecológica aplica-se ao hábitat de espécies em risco de extinção ou detentoras de processos ecológicos e biológicos importantes, como as áreas remanescentes da Mata Atlântica na Costa do Descobrimento, situados em território brasileiro. Por fim, a relevância científica de áreas que contenham formações ou fenômenos naturais relevantes para o conhecimento científico da história natural do planeta, como as Montanhas Rochosas nos EUA e Canadá (Scifoni, 2006, p. 143).

Na década de 1980, associações ambientalistas e os movimentos sociais de diversas partes do mundo passaram a discutir alternativas de desenvolvimento e a acompanhar as reuniões das Nações Unidas, exercendo um papel indutivo em diversas iniciativas de formulação e elaboração de políticas ambientais (Ribeiro, 2003, p. 532). Esse momento corresponde ao crescimento da mobilização dos ambientalistas que passaram a influenciar cada vez mais na formulação e implementação de políticas e na promoção de estratégias para a conservação ambiental.

Os anos de 1990 confirmaram que a preocupação com a conservação dos recursos naturais tornara-se internacional. Logo no início da década, ocorreu a Conferência das Nações Unidas para o Meio Ambiente e Desenvolvimento, a Conferência do Rio, em 1992, que teve o objetivo de regular a ação humana em relação à emissão de gases que afetam o efeito-estufa e ao acesso à informação genética. Nela foram celebradas as convenções sobre mudanças climáticas e sobre diversidade biológica e assinados documentos que contêm um conjunto de princípios a respeito dos recursos genéticos e da soberania de cada país sobre o patrimônio existente em seu território. Um ponto alto da Convenção 
sobre a Diversidade Biológica ocorreu quando se buscaram políticas destinadas a garantir os direitos dos povos indígenas e das populações tradicionais sobre os recursos genéticos, haja vista a estreita relação entre a preservação desses recursos e os conhecimentos, costumes e tradições dessas populações (Zanirato e Ribeiro, 2006 e 2007).

A relação estabelecida entre a preservação dos recursos e os conhecimentos tradicionais expressa a importância da diversidade cultural da humanidade. As comunidades e a cultura, em seus distintos gêneros de vida, são vistas como “ingredientes básicos da humanidade que dão sentidos e conteúdos ao princípio abstrato da igualdade" (Jelin, 1996, p. 21). A diversidade converteu-se, assim, num elemento constitutivo da universalidade.

O reconhecimento de que a diversidade cultural é intrínseca à humanidade deu-se em 2005, quando foi aprovada a Convenção sobre a Proteção e Promoção da Diversidade das Expressões Culturais. Nessa ocasião, ficou estabelecido pelos estados-partes que a diversidade cultural é uma característica essencial da humanidade, constituindo, em si, um patrimônio que deve ser valorado e preservado. Destacou-se, nesse momento, a necessidade de incorporar a cultura como um elemento estratégico das políticas de desenvolvimento nacional e internacional e a importância dos conhecimentos tradicionais como fonte de riqueza material e imaterial que podem servir para o polêmico desenvolvimento sustentável (Convención, 2005). ${ }^{2}$

Os signatários proclamaram também a importância dos direitos de propriedade intelectual para sustentar os que participam da criatividade cultural. Uma questão bastante controversa, posto que nela se insere a propriedade coletiva dos conhecimentos tradicionais. Esta Convenção reforça a necessidade da construção de uma sociedade multicultural no século XXI.

Ainda que o conhecimento tradicional, como uma forma específica de saber, tenha sido afirmado como um bem na Convenção da Diversidade Biológica, permanece em aberto a questão de como preservar sem congelar esse saber e

\footnotetext{
${ }^{2} \mathrm{O}$ desenvolvimento sustentável é talvez o mais polêmico tema discutido na ordem ambiental internacional. Ele procura associar uma matriz econômica, o desenvolvimento, a outra de origem biológica, a sustentabilidade. Inúmeros pesquisadores desqualificaram essa associação, como Martinez-Alier (1992, 1998 e 2007) e Gonçalves (1989). Entretanto, outros afirmam que se trata de uma nova possibilidade de reprodução da vida, como defendem Leff (2000, 2001 e 2001-a) e Sachs (1993). Por seu turno, Ribeiro et. al. (1996) e Ribeiro (2001) indicam que a sustentabilidade pode ser uma alternativa desde que envolva uma nova ética que desconsidere como fim a acumulação capitalista e passe a ponderar os diversos ritmos da natureza no uso dos recursos naturais.
} 
como remunerá-lo, uma vez que ele é produto de uma coletividade (Cunha, 1999, p. 160).

Estas questões permanecem polêmicas até a presente data, como pôde se perceber na Oitava Conferência das Partes da Convenção de Diversidade Biológica, ocorrida em Curitiba, em maio de 2006, quando milhares de delegados discutiram o papel do conhecimento das comunidades tradicionais e sua apropriação e uso pelo Ocidente. As dificuldades em chegar a um consenso quanto a esse assunto postergaram sua discussão para 2010, na Décima Conferência das Partes. Enquanto isso, assiste-se à realização de contratos entre empresas transnacionais - em especial do setor de fármacos - e comunidades tradicionais, sem regulamentação internacional dada a diversidade de instrumentos jurídicos internacionais que abordam a matéria, como demonstraram Zanirato e Ribeiro, (2007).

Esses aspectos atinentes à preservação do patrimônio natural indicam a premência de articular interesses diversos que, muitas vezes, extrapolam territórios nacionais. Eles se expressam nos debates em torno das conferências temáticas e normativas. Devido a esse jogo político, nem sempre a aplicação de uma convenção ocorre em deliberada e estreita articulação com as convenções afins. Ao mesmo tempo, o quadro revela quão candentes têm sido as discussões a respeito da ampliação do conceito de patrimônio e as implicações daí decorrentes.

O Brasil, por deter informação genética em escala relevante, adquire posição estratégica na conservação da natureza mundial. Por isso é fundamental apresentar os instrumentos disponíveis para essa ação no país.

\section{Proteção do patrimônio natural brasileiro na escala federal}

Apesar de o conceito de patrimônio natural propriamente dito somente ter se consolidado mundialmente a partir da Convenção do Patrimônio de 1972, a idéia e os instrumentos para a instituição de proteção desse tipo de patrimônio manifestaram-se bem antes no Brasil.

É o que pode ser constatado no artigo $10^{\circ}$ da Constituição de 1934 que empregou, pela primeira vez como dever do Estado, tanto no âmbito federal como no estadual, "a proteção das belezas naturais e os monumentos de valor histórico ou artístico” (Constituição, 1934).

Este documento também trouxe um dispositivo essencial para a proteção do patrimônio no Brasil: a determinação, conforme o artigo $113^{\circ}$, de que o direito de propriedade não poderia ser exercido "contra o interesse social e coletivo". 
Essa outra forma de entender a propriedade possibilitou a alienação do bem e a efetiva proteção legal do patrimônio.

Em se tratando dos bens naturais, foram promulgados nesse momento o Código de Minas e o Código de Águas que deram as bases para a nacionalização das riquezas do subsolo.

A Constituição de 1937 reafirmou a sujeição do instituto de propriedade ao interesse coletivo. Apesar de ter permanecido como um direito individual, sujeitava-se à ingerência do Estado para cumprir sua função social.

Esta Constituição, bem como o Decreto-lei no 25/1937 mantiveram a atribuição do Estado para com o patrimônio, substituindo, entretanto, o termo "belezas naturais" por "monumentos naturais" e por "paisagens ou lugares dotados pela natureza". É o que pode ser observado no artigo 134 quando estabeleceu que "os monumentos históricos, artísticos e naturais, assim como as paisagens ou locais particularmente dotados pela natureza gozam de proteção e dos cuidados especiais da nação, dos Estados e dos Municípios". Esse mesmo artigo também definiu que os atentados cometidos contra os monumentos e as paisagens "serão equiparados aos cometidos contra o patrimônio nacional" (Constituição, 1937).

Encerra-se, nesse dispositivo, o entendimento de que a natureza e a cultura devem estar sob a tutela do Estado, haja vista o interesse social de que ambas podem ser dotadas. A mesma associação encontra-se no Decreto-lei no 25/1937 quando definiu, como patrimônio histórico e artístico nacional, os "monumentos naturais, sítios e paisagens de feição notável dotada pela natureza ou agenciados pela indústria humana”. Este decreto normatizou a atividade de preservação dos bens e definiu o tombamento como "o instituto jurídico através do qual o poder público determina que os bens culturais sejam objetos de proteção". Ele ainda fixou o modo como deve ocorrer essa proteção.

O tombamento é assim um procedimento jurídico pelo qual se faz a proteção do monumento que se efetiva ao ser inscrito no livro do tombo. Ele é tanto o ato administrativo quanto a operação de inscrição do objeto em um dos livros de tombo: arqueológico, etnográfico, paisagístico, histórico, das belas artes e das artes aplicadas. Os efeitos jurídicos sobre o patrimônio tombado restringem a alienação, a alteração da paisagem da vizinhança e a modificação do bem. Por fim, obriga o proprietário a conservá-lo (Silva, 2003, p. 139).

Nesses primeiros anos após o Decreto-lei $\mathrm{n}^{\circ} 25$, apesar da ênfase dada à preservação de monumentos arquitetônicos, foram tombadas algumas áreas 
naturais no município do Rio de Janeiro em função da ameaça de construção, no topo do Pão de Açúcar, de um restaurante e uma nova estação de bondes (Fonseca, 1996, p. 59).

A Constituição de 1946 manteve a proteção patrimonial do Estado e estendeu a salvaguarda aos documentos históricos, mas deixou de equiparar os atentados aos bens tombados aos atentados cometidos contra o patrimônio nacional (Constituição, 1946). A Carta de 1967 também manteve esses dispositivos e ampliou o conceito de patrimônio ao incluir jazidas arqueológicas (Constituição, 1967).

Nos anos 1960, a legislação em defesa do patrimônio nacional foi reforçada com a criação de leis que regulamentaram o patrimônio natural. Entre elas a Lei dos Sambaquis - Lei n 3.924/1961 que regulamentou os achados arqueológicos e pré-históricos; o Código Florestal - Lei n 4.771/1965 que considerou a floresta como de interesse comum a todos os habitantes do país e fixou áreas de preservação permanente, e a Lei de Proteção à Fauna - Lei n 5.197/1967. Também nessa década foi criado, pelo Decreto n 289/1967, o Instituto Brasileiro de Desenvolvimento Florestal - IBDF, encarregado de gerenciar o setor florestal brasileiro por meio de incentivos ao reflorestamento.

Como desdobramento da Conferência de Estocolmo de 1972, foi criada, em 1973 por meio do Decreto $n^{\circ} 73.030$, no âmbito do Ministério do Interior, a Secretaria Especial do Meio Ambiente - Sema que recebeu a incumbência de administrar os recursos ambientais e controlar as estações ecológicas e as áreas de proteção ambiental.

Em agosto de 1981, foi sancionada a Lei ${ }^{\circ}$ 6.938, relativa à Política Nacional do Meio Ambiente, que definiu o papel do poder público e as responsabilidades do setor privado no que tange à proteção ambiental. Esta Lei permitiu a criação do Conselho Nacional de Meio Ambiente - Conama, em 1986, com poder deliberativo e competências para estabelecer normas, critérios e padrões relativos ao controle e à manutenção da qualidade do meio ambiente, com vistas ao uso racional dos recursos ambientais. Uma das características marcantes do Conama, desde seu início, foi a participação da sociedade civil por meio de representações de movimentos ambientalistas e sociais.

Na reforma do estado de 1989, entendeu-se que a Sema e o IBDF tinham atribuições paralelas. Por isso, foram fundidos a outros dois órgãos: a Superintendência da Borracha - Sudhevea e a Superintendência da Pesca - Sudepe. Disso resultou o Instituto Brasileiro do Meio Ambiente e dos Recursos Naturais 
Renováveis - Ibama, criado por meio da Lei $\mathrm{n}^{0} 7.735$, de 22 de fevereiro de 1989, órgão responsável pelo licenciamento ambiental, gestão das unidades de conservação federais e pela execução da Política Nacional do Meio Ambiente. Porém, em 2007 o Ibama foi dividido por meio da Medida Provisória n 366, de 2007. Criou-se o Instituto Chico Mendes para cuidar das áreas naturais protegidas, enquanto os licenciamentos foram mantidos a cargo do Ibama.

Desde 1977, o Brasil havia se tornado signatário da Convenção do Patrimônio Mundial de 1972. Como conseqüência disso, a cidade de Ouro Preto foi alçada à condição de Patrimônio da Humanidade pela Unesco, em 1980, o que inaugurou a presença brasileira na lista mundial. Em 1986, o país inscreveu seu primeiro patrimônio natural, o Parque Nacional de Iguaçu nessa mesma lista. ${ }^{3}$

A década de 1980 também pode ser entendida como bastante positiva para a salvaguarda dos bens naturais, pois nela deu-se ainda a promulgação da Constituição de 1988 que estabeleceu um conceito mais amplo de patrimônio cultural ao incluir o patrimônio natural e o imaterial como foco da ação das políticas patrimoniais. Nela, o patrimônio natural aparece como "sítios de valor paisagístico e ecológico", o que indica, por um lado, a valorização dos aspectos estéticos, herança do conceito de monumento natural e, por outro, o reconhecimento de um aspecto até então não considerado: o ecológico, ou seja, a importância dos fatores, das relações e dos processos estabelecidos na dinâmica da natureza.

De acordo com o artigo 216 da Constituição, o patrimônio cultural brasileiro é constituído por "bens de natureza material e imaterial, tomados individualmente ou em conjunto, portadores de referência à identidade, à ação, à memória dos diferentes grupos formadores da sociedade brasileira". Entre os bens inserem-se: I - as formas de expressão; II - os modos de criar, fazer e viver; III - as criações científicas, artísticas e tecnológicas; IV - as obras, objetos, documentos, edificações e demais espaços destinados às manifestações artístico-culturais; $\mathrm{V}$ - os conjuntos urbanos e sítios de valor histórico, paisagístico, artístico, arqueológico, paleontológico, ecológico e científico (Constituição, 1988).

\footnotetext{
${ }^{3}$ Em 2006, a presença brasileira na Lista Mundial do Patrimônio da Humanidade incluía os itens a seguir: Parque Nacional do Jaú, Ouro Preto, Olinda, São Miguel das Missões, Salvador, Congonhas do Campo, Parque Nacional do Iguaçu, Brasília, Parque Nacional Serra da Capivara, Centro Histórico de São Luís, Diamantina, Pantanal Matogrossense, Costa do Descobrimento, Reserva Mata Atlântica, Reservas do Cerrado, Centro Histórico de Goiás e Ilhas Atlânticas. Fonte: www. iphan.gov.br, acesso em janeiro de 2008.
} 
Em conformidade com esse dispositivo, compete ao governo federal, por meio do Ministério da Cultura, formular e operacionalizar a política patrimonial, ou seja, criar instrumentos e mecanismos que possibilitem a proteção, a preservação e a difusão do patrimônio cultural brasileiro. Entre os instrumentos estão: o inventário, o registro, a vigilância, o tombamento, a desapropriação e outras formas de acautelamento e preservação.

Até o ano de 2005, o governo federal, por meio do Instituto do Patrimônio Histórico e Artístico Nacional - Iphan, tombou 38 itens como patrimônio natural (quadro 1).

Entre os bens tombados constata-se a valorização de aspectos geomorfológicos que representam $42 \%$ do total e áreas verdes urbanas que correspondem a 32\%. Também se percebe que há uma classificação do patrimônio natural "a partir de seus significados reconhecidos por meio do tombamento: ou como testemunhos da natureza senso estrito, ou como um complemento de outros atributos que se deseja preservar" (Scifoni, 2006, p. 93).

Quanto aos aspectos geomorfológicos, percebe-se que há um critério estético-paisagístico, mas que evidencia uma relevância do ponto de vista de processos naturais, como o Pico do Itabirito, um maciço de hematita compacta; ${ }^{4}$ da Serra do Curral, considerada um marco geográfico de beleza paisagística, da Pedra da Gávea e do Pão de Açúcar, enormes blocos graníticos; da Gruta do Lago Azul que se destaca pela forma atípica de seus espeleotemas e por conter material paleontológico (ossadas de mamíferos pleistocenos). Nas áreas verdes urbanas, tem-se o Parque e Fonte do Queimado, uma área de mananciais coberta com vegetação abundante; o Parque e Museu Emílio Goeldi que conta com uma das mais representativas coleções de flora e fauna amazônica; a Gruta da Mangabeira, na qual se incluem grandes jazidas de fósseis e que se destaca principalmente pelo seu papel simbólico-religioso, ligado às procissões de romeiros que anualmente se direcionam ao local; a Serra da Barriga, tombada a partir da pressão do movimento negro, local no qual se constituiu o mais importante quilombo da história brasileira, Palmares, entre outros (Scifoni, 2006).

\footnotetext{
${ }^{4}$ Que teve seu tombamento anulado por decisão do presidente da República em 1965 para viabilizar a exploração de minério de ferro pela Companhia Siderúrgica Nacional.
} 


\begin{tabular}{|c|c|c|c|}
\hline \multicolumn{4}{|c|}{ Quadro 1 - Patrimônio natural tombado pelo Iphan até 2005} \\
\hline $\begin{array}{l}\text { Tipo- } \\
\text { logia }\end{array}$ & Bem tombado & Local & $\begin{array}{c}\text { Ano do } \\
\text { tomba- } \\
\text { mento }\end{array}$ \\
\hline \multirow{16}{*}{ 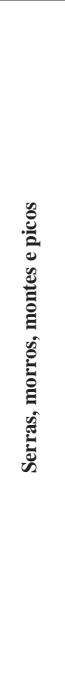 } & Serra do Monte Santo & Monte Santo/BA & 1983 \\
\hline & Monte Pascoal & Porto Seguro/BA & 1974 \\
\hline & Serra da Barriga & União dos Palmares/AL & 1986 \\
\hline & Serra do Curral & Belo Horizonte/MG & 1960 \\
\hline & Pico do Itabirito & Itabirito/MG & 1962 \\
\hline & Penhasco do Corcovado & Rio de Janeiro/RJ & 1973 \\
\hline & Morro Cara de Cão & Rio de Janeiro/RJ & 1973 \\
\hline & Morro da Babilônia & Rio de Janeiro/RJ & 1973 \\
\hline & Morro da Urca & Rio de Janeiro/RJ & 1973 \\
\hline & Penhasco dos Dois Irmãos & Rio de Janeiro/RJ & 1973 \\
\hline & Morro do Pão de Açúcar & Rio de Janeiro/RJ & 1973 \\
\hline & Penhasco da Pedra da Gávea & Rio de Janeiro/RJ & 1973 \\
\hline & Morros do Distrito Federal & Rio de Janeiro/RJ & 1938 \\
\hline & Morro do Valongo & Rio de Janeiro/RJ & 1938 \\
\hline & Morro do Pai Inácio e Rio Mucujezinho & Palmeiras/BA & 2000 \\
\hline & Dedo de Deus & Guapimirim/RJ & s/data \\
\hline \multirow{2}{*}{$\begin{array}{c}\text { Gru- } \\
\text { tas }\end{array}$} & Da Mangabeira & Ituaçu/BA & 1962 \\
\hline & De Bonito, Grutas do Lago Azul & Bonito/MS & 1978 \\
\hline \multirow{4}{*}{ 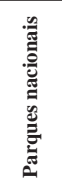 } & Parque Nacional Serra da Capivara & $\begin{array}{l}\text { São Raimundo Nonato, Brejo do Piauí, Coronel } \\
\text { José Dias e João Costa/PI }\end{array}$ & 1993 \\
\hline & Parque Nacional Florestas da Tijuca & Rio de Janeiro/RJ & 1967 \\
\hline & Parque Histórico Nacional dos Guararapes & Jaboatão dos Guararapes/PE & 1961 \\
\hline & Parque Nacional dos Serrotes do Quixadá & Quixadá/CE & s/data \\
\hline \multirow{10}{*}{ 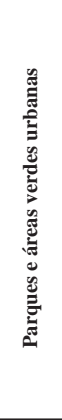 } & Parque e Fonte do Queimado & Salvador/BA & 1997 \\
\hline & Jardim Botânico & Rio de Janeiro/RJ & 1938 \\
\hline & Horto Florestal & Rio de Janeiro/RJ & 1973 \\
\hline & Parque da Cidade/Jardim São Clemente & Nova Friburgo/RJ & 1957 \\
\hline & Parque do Palácio Imperial & Petrópolis/RJ & 1938 \\
\hline & Parque da Independência e Museu Paulista & São Paulo/SP & 1998 \\
\hline & Jardim Zoobotânico do Museu Emílio Goeldi & Belém/PA & 1994 \\
\hline & Parque Rua Marechal & Joinville/SC' & 1965 \\
\hline & Parque Henrique Lage & Rio de Janeiro/RJ & 1957 \\
\hline & Passeio Público & Rio de Janeiro/RJ & 1965 \\
\hline \multirow{4}{*}{ 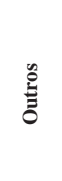 } & Ilha da Boa Viagem & Niterói/RJ & 1938 \\
\hline & Praias de Paquetá & Rio de Janeiro/RJ & 1938 \\
\hline & Município de Parati & Parati/RJ & 1974 \\
\hline & Conjunto Paisagístico da Lagoa Rodrigo de Freitas & Rio de Janeiro/RJ & 2000 \\
\hline
\end{tabular}


Confirmando a preocupação em consolidar uma normativa destinada à preservação do patrimônio natural brasileiro, foi instituída, por meio da Lei ${ }^{\circ}$ 9.433, em 1997, a Política Nacional de Recursos Hídricos que permitiu a criação do Sistema Nacional de Gerenciamento dos Recursos Hídricos. Este sistema visa garantir a utilização racional e integrada desses recursos e permitir a prevenção e a defesa contra eventos hidrológicos de origem natural ou decorrentes do uso indiscriminado dos recursos naturais. Outro órgão criado por aquela mesma lei foi o Conselho Nacional dos Recursos Hídricos que, infelizmente, não contempla todos os estados da federação em sua composição, por razões jamais expostas ao debate público, e a Agência Nacional da Água, criada pela Lei $n^{\circ}$ 9.984, de 2000, responsável pela operacionalização do Plano Nacional dos Recursos Hídricos. Além disso, também integram a gestão dos recursos hídricos os comitês de bacia que contam com representantes da sociedade que vive na bacia hidrográfica e que elaboram um plano de gestão da água com participação popular.

Do mesmo modo pode ser entendida a Lei ${ }^{\circ}$ 9.985, de 2000, que instituiu o Sistema Nacional de Unidades de Conservação (SNUC) que define o conjunto de áreas a serem protegidas no âmbito federal, estadual ou municipal. A proteção visa a manutenção da diversidade biológica e dos recursos genéticos no território nacional e nas águas jurisdicionais. De acordo com o SNUC, as unidades de conservação podem ser de proteção integral ou de uso sustentável. O primeiro tipo advoga a intocabilidade do ambiente natural, não sem gerar resistência da população local que vive nas áreas. No segundo caso, a população que vive nas áreas protegidas pode desenvolver atividades produtivas, desde que aprovadas no plano de manejo e que sejam consideradas de baixo impacto ambiental e não coloquem em risco a manutenção dos ritmos naturais do ecossistema.

Há que se considerar também a existência de outros instrumentos que se destinam a aperfeiçoar a política de proteção ao patrimônio natural brasileiro, entre eles a Lei de Crimes Ambientais, Lei n 9.605, de fevereiro de 1998, que dispõe acerca das sanções penais e administrativas derivadas de condutas e atividades lesivas ao meio ambiente.

A produção sistemática de documentos legais destinados a salvaguardar o patrimônio natural brasileiro traduz o esforço que tem havido nesta direção. A criação do Ministério do Meio Ambiente, em 1992, depois da Conferência do Rio, que passou a coordenar a conservação e a preservação de ambientes naturais em escala federal, reforçou esse movimento dos dirigentes brasileiros. Também 
se constata uma crescente conscientização da sociedade brasileira que se mobilizou para a realização de várias conferências nacionais de meio ambiente, a partir de 2003, da qual participaram milhares de representantes de empresários, universidades, movimentos sociais e ambientais, entre outros segmentos. No entanto, ainda persiste o desafio de aplicar os dispositivos firmados de forma a impedir a devastação da natureza brasileira, detentora da maior diversidade biológica do mundo, e a permitir que a geração atual e as gerações futuras possam usufruir as vantagens que essa riqueza propicia.

A seguir, algumas experiências desenvolvidas em escala estadual apontam outras possibilidades de conservação ambiental no Brasil.

\section{Proteção do patrimônio natural brasileiro na esfera estadual}

A proteção do patrimônio natural já era objeto de experiências levadas a cabo em alguns estados da federação, décadas antes da edição da Constituição de 1988.

É o caso do Estado do Paraná que criou, em 1948, dentro da Secretaria de Educação e Cultura, a Divisão do Patrimônio Histórico, Artístico e Cultural do Paraná para a "defesa e restauração dos monumentos e conservação das paisagens e formações naturais características do Estado" (Kersten, 2000, p. 132).

Em 1953, foi editada a Lei ${ }^{\circ} 1.211$, relativa à proteção do patrimônio histórico, artístico e natural do Paraná. Apesar de ser a primeira referência no país a respeito do patrimônio natural, definido como "os monumentos naturais, os sítios e paisagens que importa conservar e proteger pela feição notável com que tenham sido dotados pela natureza ou agenciados pela indústria humana", esta lei só entrou em vigor na década de 1960, quando foram tombados os primeiros monumentos do Estado (idem, p. 138-139).

Pode-se dizer que o Paraná "foi pioneiro também em ações de maior magnitude" no que tange ao patrimônio natural, uma vez que seus tombamentos, entre as décadas de 1960 e 1980 (quadro 2), foram de maior extensão e complexidade, como se deu ao tombar a Ilha do Mel, a paisagem da orla, o Parque de Vila Velha e a Serra do Mar (Scifoni, 2006). 


\begin{tabular}{|c|c|c|}
\hline \multicolumn{3}{|c|}{ Quadro 2 - Patrimônio natural tombado no Paraná, até 2005} \\
\hline Ano de tombamento & bem & Município \\
\hline 1966 & $\begin{array}{c}\text { Parque de Vila Velha, Furnas e Lagoa } \\
\text { Dourada }\end{array}$ & Ponta Grossa \\
\hline 1970 & Paisagem da orla marítima & Matinhos \\
\hline \multirow{5}{*}{1974} & Árvore - paineira & Campina Grande do Sul \\
\hline & Árvore - angico branco & Curitiba \\
\hline & Árvore - corticeira & Curitiba \\
\hline & Árvore - tipuana & Curitiba \\
\hline & Passeio Público & Curitiba \\
\hline 1975 & Ilha do Mel & Paranaguá \\
\hline 1976 & Árvores da praça Santos Dumont & Curitiba \\
\hline 1982 & Sambaquis & Paranaguá \\
\hline 1983 & Capão da Imbuia & Curitiba \\
\hline 1985 & Ilha de Superagui & Guaraqueçaba \\
\hline 1986 & Serra do Mar & $\begin{array}{c}\text { Antonina, Guaraqueçaba, Guaratuba,Piraquara, } \\
\text { Quatro Barras, São José dos Pinhais, } \\
\text { Tijucas do Sul, Campina Grande do Sul }\end{array}$ \\
\hline 1988 & Gruta da Lancinha & Rio Branco do Sul \\
\hline \multirow{3}{*}{1990} & Árvore - ceboleira & Curitiba \\
\hline & Árvore - palmeira & Morretes \\
\hline & Árvore - carvalho & São Matheus do Sul \\
\hline
\end{tabular}

Minas Gerais também desenvolveu ações de preservação da natureza antes da Constituição de 1988. A estratégia do Estado para este fim foi a de priorizar paisagens que expressavam formas de relevo em destaque no contexto regional, tais como serras e altos picos rochosos. Mas o grande impulso deu-se nos anos 1980, com a Constituição de 1989 do Estado que instituiu patrimônios naturais reconhecidos. No quadro 3 encontra-se a lista de bens tombados em Minas Gerais.

O Rio de Janeiro foi outro Estado que iniciou o tombamento de seu patrimônio natural antes de 1988. A partir de 1965, uma grande parte desse patrimônio já havia sido tombado, como indica o quadro 4. Nessas ações, observam-se a diversidade de tipologias, que vai desde áreas verdes urbanas a serras, morfologias costeiras, praias e ilhas. 


\begin{tabular}{|c|c|c|}
\hline \multicolumn{3}{|c|}{ Quadro 3 - Patrimônio natural tombado em Minas Gerais, até 2005} \\
\hline Ano de tombamento & Bem & Município \\
\hline 1977 & Lagoa e Lapa do Sumidouro & Lagoa Santa e Pedro Leopoldo \\
\hline 1978 & Serra de Ouro Branco & Ouro Branco \\
\hline \multirow{7}{*}{1989} & Serra da Piedade & Caeté \\
\hline & Serra do Caraça & Catas Altas \\
\hline & Bacia Hidrográfica do Jequitinhonha & Diversos \\
\hline & Pico do Ibituruna & Governador Valadares \\
\hline & Pico do Itabirito & Itabirito \\
\hline & Serra da Ibitiboca & Lima Duarte \\
\hline & Serra de São Domingos & Poços de Caldas \\
\hline 1996 & Conjunto arqueológico e paisagístico Poções & Matozinhos \\
\hline 1999 & Cachoeiras do Tombo da Fumaça & Salto da Divisa \\
\hline 2000 & Serra dos Cristais & Diamantina \\
\hline
\end{tabular}

\begin{tabular}{|c|c|c|}
\hline \multicolumn{3}{|c|}{ Quadro 4 - Patrimônio natural tombado no Rio de Janeiro até 2005} \\
\hline Ano de tombamento & Bem & Município \\
\hline \multirow{3}{*}{1965} & Paulo Henrique Lage & Rio de Janeiro \\
\hline & Parque da Gávea/Parque da Cidade & Rio de Janeiro \\
\hline & Ilha do Brocoió & Rio de Janeiro \\
\hline 1967 & Árvores de Paquetá & Rio de Janeiro \\
\hline 1968 & Figueira gigante & Rio de Janeiro \\
\hline 1975 & Morro do Urubu & Rio de Janeiro \\
\hline \multirow{5}{*}{1983} & Pontal de Sernambetiba & Rio de Janeiro \\
\hline & Morro do Amorim & Rio de Janeiro \\
\hline & Morro do Cantagalo & Rio de Janeiro \\
\hline & Morro da Portela & Rio de Janeiro \\
\hline & Pedra da Baleia & Rio de Janeiro \\
\hline 1985 & Praia do Grumari & Rio de Janeiro \\
\hline \multirow{5}{*}{1987} & Litoral Fluminense - Foz do Rio Paraíba do Sul & São Francisco de Itapoana, São João da Barra \\
\hline & Ilha Grande & Angra dos Reis \\
\hline & $\begin{array}{l}\text { Litoral Fluminense; Canto sul da Praia Itaipu e } \\
\text { ilhas da Menina, da Mãe e do pai }\end{array}$ & Niterói \\
\hline & Litoral Fluminense & Paraty \\
\hline & Pedra do Sal & Rio de Janeiro \\
\hline \multirow{2}{*}{1988} & Dunas & Arraial do Cabo \\
\hline & Dunas & Cabo Frio \\
\hline 2003 & Bens naturais do litoral de Armação de Búzios & Armação de Búzios \\
\hline
\end{tabular}


No Estado de São Paulo, as primeiras iniciativas ocorreram logo nos primeiros anos de fundação do Conselho de Defesa do Patrimônio Histórico, Arqueológico, Artístico e Turístico - Condephaat, que se deu em 1968.

A partir de meados da década de 1970, o Condephaat realizou uma série de tombamentos de áreas naturais no Estado, como a nascente do Rio Tietê, a Reserva Estadual da Cantareira, as serras do Japi e a do Mar, além de áreas urbanas, como os bairros dos Jardins e do Pacaembu, ou os parques da Aclimação, Siqueira Campos e Ibirapuera.

A prática preservacionista em São Paulo foi bastante marcada por conflitos que envolvem a questão da propriedade; basta lembrar a iniciativa do Condephaat de preservar os casarões da avenida Paulista que resultou na destruição de grande parte daqueles imóveis, pois os proprietários não aceitaram as decisões do poder público (Rodrigues, 1996, p. 198). No quadro 5, a seguir, encontramse os bens tombados no Estado de São Paulo.

\begin{tabular}{|c|c|c|}
\hline \multicolumn{3}{|c|}{ Quadro 5 - Patrimônio natural tombado em São Paulo, até 2005} \\
\hline Bem tombado & Ano do pedido & tombamento \\
\hline 1. Bosque dos Jequitibás & 1969 & 1970 \\
\hline 2. Parque das Monções & 1969 & 1972 \\
\hline 3.Caminho do Mar & 1972 & 1972 \\
\hline 4. Pedreira de Varvitos & 1969 & 1974 \\
\hline 5. Parque da Independência & 1969 & 1975 \\
\hline 6. Horto Florestal de Rio Claro & 1974 & 1977 \\
\hline 7.Maciço da Juréia & 1973 & 1979 \\
\hline 8.Reserva Florestal do Morro Grande & 1978 & 1981 \\
\hline 9. Jardim da Luz & 1977 & 1981 \\
\hline 10. Parque Siqueira Campos & 1978 & 1982 \\
\hline 11.Mata Santa Genebra & 1982 & 1983 \\
\hline 12. Vila de Picinguaba & 1983 & 1983 \\
\hline 13. Parque Estadual do Jaraguá & 1978 & 1983 \\
\hline 14.Serras do Japi, Guaxinduva e Jaguacoara & 1974 & 1983 \\
\hline 15. Serra de Atibaia & 1982 & 1983 \\
\hline 16. Serra de Voturuna & 1983 & 1983 \\
\hline 17. Reserva Estadual Cantareira e Horto Florestal & 1978 & 1983 \\
\hline 18. Morro do Botelho & 1983 & 1984 \\
\hline 19. Serra do Mar & 1976 & 1985 \\
\hline 20. Morros do Icanhema, do Pinto e do Monduba & 1978 & 1985 \\
\hline 21. Parque da Aclimação & 1983 & 1986 \\
\hline 22. Jardins América, Europa, Paulista e Paulistano & 1985 & 1986 \\
\hline
\end{tabular}




\begin{tabular}{|c|c|c|}
\hline Bem tombado & Ano do pedido & Tombamento \\
\hline 23.Casa Modernista & 1983 & 1986 \\
\hline 24. Vila de Paranapiacaba & 1983 & 1987 \\
\hline 25. Vale do Quilombo & 1986 & 1988 \\
\hline 26. Haras São Bernardo & 1986 & 1990 \\
\hline 27. Nascentes do Tietê & 1974 & 1990 \\
\hline 28. Pacaembu & 1985 & 1991 \\
\hline 29. Serra do Guararu & 1988 & 1992 \\
\hline 30. Parque do Ibirapuera & 1983 & 1992 \\
\hline 31. Rocha Moutonnée & 1975 & 1992 \\
\hline 32. Chácara Tangará & 1989 & 1994 \\
\hline 33. Parque do Povo & 1988 & 1994 \\
\hline 34. Ilhas do Litoral Paulista & 1989 & 1994 \\
\hline 35. Parque da Água Branca & 1983 & 1996 \\
\hline 36. Cratera de Colônia & 1994 & 2003 \\
\hline 37. Morro Juquery (Pico Olho D'Água) & 1983 & 2004 \\
\hline Fonte: Condephaat. Adap. de Scifoni, 2006. & & \\
\hline
\end{tabular}

Destaca-se, nas ações paulistas, a diversidade de patrimônios naturais reconhecidos: manchas de vegetação nativa remanescente, áreas verdes urbanas constituídas por uma vegetação não nativa e implantada, extensas áreas constituídas por maciços serranos e morros e estruturas geológicas peculiares.

A diversidade é explicada, segundo Scifoni (2006), pela presença do conselheiro e geógrafo Aziz Ab'Saber no corpo do Condephaat. Ab'Saber se propôs a orientar uma política de ação dentro do Condephaat "que deveria ocupar-se em identificar e proteger um importante patrimônio natural constantemente ameaçado diante da expansão do processo de urbanização do território". Somado a isso, havia "um movimento de renovação do próprio conceito de patrimônio" que se voltava para os bens ambientais urbanos, num entendimento de que "patrimônio natural não se referia somente a testemunhos de uma beleza natural excepcional", mas que reconhecia o valor "de uma natureza transformada e apropriada socialmente", presente nos parques e áreas verdes urbanas (Scifoni, 2006, p. 107- 116).

Há que salientar que, em São Paulo, parte significativa das áreas naturais tombadas, ou seja, $44 \%$, resultou de pedidos da sociedade civil. Ainda assim, persiste o desafio de fazer com que a legislação existente seja cumprida e aperfeiçoada ainda mais, de forma a proteger o patrimônio para a geração atual e para as futuras gerações, em que pesem os interesses particulares.

As experiências desenvolvidas em unidades da federação confirmam que o Brasil dispõe de diversos instrumentos jurídicos que se complementam 
aos federais. Cabe à população se apropriar de tais normas com vistas a uma definição mais ampla de conservação da natureza de modo a evitar conflitos socioambientais, em especial com aqueles que habitam as áreas naturais que geram interesses conservacionistas.

\section{Considerações finais}

A formulação de uma normativa jurídica voltada à proteção do patrimônio natural e a organização de uma estrutura administrativa especializada nesse propósito demonstram o reconhecimento da necessidade de salvaguardar nosso legado. Também demonstram a responsabilidade do Estado e da sociedade no que tange à conservação da natureza.

No entanto, há que se ter em conta as dificuldades que se colocam para deter o nível atual de devastação ambiental. Interesses diversos, como os de madeireiros, povos indígenas, fazendeiros, trabalhadores rurais sem terra, apenas para listar alguns dos mais importantes segmentos sociais do Brasil contemporâneo, indicam que a sociedade deve refletir sobre ao menos dois aspectos quando o assunto é a conservação ambiental: quem ganha e quem perde com a manutenção da diversidade biológica e demais feições naturais? Quais os objetivos da manutenção desse patrimônio? Somente quando essas perguntas forem respondidas teremos perspectivas de gestão do ambiente natural de forma mais democrática e igualitária, distribuindo os benefícios que ela pode e deve propiciar às gerações presentes e futuras.

É preciso enfrentar criticamente os interesses que se contrapõem à salvaguarda do patrimônio natural, sob pena de nos depararmos, em curto prazo, com a perda da biodiversidade, a desertificação do solo e os efeitos do aquecimento do planeta. Esse enfrentamento será político. A normativa jurídica aqui exposta prevê em muitos foros a participação popular e poderá servir para o debate. Ou, poderá apenas legitimar interesses ocultos à população brasileira. A mobilização permanente e qualificada pode evitar que a segunda alternativa impere.

\section{Referências bibliográficas}

CHOAY, Françoise. A alegoria do patrimônio. São Paulo: Edunesp/Estação Liberdade, 2001.

CONVENCION para la protección del patrimonio mundial natural y cultural, 1972. Disponível em www.unesdoc.unesco/org/. Acesso em 22 de abril de 2006.

CONVENCION sobre la protección y promoción de la diversidad de las expresiones 
culturales. 2005. Disponível em www.unesdoc.unesco/org/. Acesso em 26 de junho de 2006.

CONSTITUIÇÃO da República Federativa do Brasil, 1934. Disponível em www. planalto.gov.br/legislaçao. Acesso em 1 de julho de 2006.

CONSTITUIÇÃO da República Federativa do Brasil, 1937. Disponível em www. planalto.gov.br/legislaçao. Acesso em 1 de julho de 2006.

CONSTITUIÇÃO da República Federativa do Brasil, 1946. Disponível em www. planalto.gov.br/legislaçao. Acesso em 1 de julho de 2006.

CONSTITUIÇÃO da República Federativa do Brasil, 1967. Disponível em www. planalto.gov.br/legislaçao. Acesso em 1 de julho de 2006.

CONSTITUIÇÃO da República Federativa do Brasil, 1988. Disponível em www. planalto.gov.br/legislaçao. Acesso em 1 de julho de 2006.

CUNHA, Manuela Carneiro da. Populações tradicionais e a Convenção da Diversidade Biológica. São Paulo: Estudos Avançados, 1999, p. 147-163.

DECLARACION de la Conferencia de las Naciones Unidas sobre el Medio Ambiente Urbano. Disponível em www.prodiversitas.bioetica.org $/ \mathrm{dco} 89 \mathrm{htm}$. Acesso em 2 de julho de 2006.

FONSECA, Maria Cecília Londres. Da modernização à participação: a política federal de preservação nos anos 70 e 80. Revista do Patrimônio Histórico e Artístico Nacional. Brasília, no 24, 1996, p. 153-163.

GONÇALVES, Carlos Walter P. Os (des)caminhos do meio ambiente. São Paulo: Contexto, 1989.

JELIN, E. Cidadania e alteridade: o reconhecimento da pluralidade. Revista do Patrimônio. Rio de Janeiro: Iphan, 1996, p. 15-25.

KERSTEN, Márcia S. de Andrade. Os rituais de tombamento e a escrita da história. Curitiba: Editora UFPR/Imprensa Oficial do Paraná, 2000.

LEFF, Enrique. Epistemologia ambiental. São Paulo: Cortez, 2001.

LEFF, E. Saber ambiental: sustentabilidade, racionalidade, complexidade, poder. Petrópolis: Vozes, 2001-a.

LEFF, E. Ecologia, capital e cultura: racionalidade ambiental, democracia participativa e desenvolvimento sustentável. Blumenau : Furb, 2000.

MARTINEZ-ALIER, J. Ecologismo dos pobres. São Paulo: Contexto, 2007.

MARTINEZ-ALIER, J. Da economia ecológica ao ecologismo popular. Blumenau: Furb, 1998.

MARTÍNEZ-ALIER, J. Ecología y pobreza. Valencia: Centre Cultural Bancaixa, 1992.

NAZO, Georgette Nacarato e MUKAI, Toshio. O direito ambiental no Brasil: evolução histórica e a relevância do direito internacional do meio ambiente. In: RIBEIRO, Wagner. (org.) Patrimônio ambiental brasileiro. São Paulo: Edusp/ 
Imprensa Oficial do Estado de São Paulo, 2003. p. 91-124.

RECOMENDACIÓN relativa a la protección de la belleza y el carácter de los lugares y paisajes, 1962. Disponível em www.unesdoc.unesco/org/. Acesso em 2 de julho de 2006.

RIBEIRO, W. C. A ordem ambiental internacional. São Paulo: Contexto, 2001.

RIBEIRO, W. C. (org.). Patrimônio ambiental brasileiro. São Paulo: Edusp/Imprensa Oficial do Estado de São Paulo, 2003.

RIBEIRO, W. C. Desenvolvimento sustentável e segurança ambiental global. Biblio 3 W, Revista Bibliográfica de Geografía y Ciencias Sociales. Universidad de Barcelona, vol. VI, no 312, 2001, p. 1-10, http://www.ub.es/geocrit/b3w-312.htm.

RIBEIRO, W. C. et al. Desenvolvimento sustentável: mito ou realidade? Terra Livre, 1996, v. 11, p. 91-101.

RIBEIRO, W. C. O Brasil na ordem ambiental internacional. In: RIBEIRO, Wagner. (org.) Patrimônio ambiental brasileiro. São Paulo: Edusp/Imprensa Oficial do Estado de São Paulo, 2003. p. 601-619.

RODRIGUES, Marly. De quem é o patrimônio: um olhar sobre a prática preservacionista em São Paulo. Revista do Patrimônio Histórico e Artístico Nacional, $\mathrm{n}^{\circ} 24,1996$, p. 195-203.

SACHS, Ignach. Estratégias de transição para o século XXI: desenvolvimento e meio ambiente. São Paulo: Nobel/Fundap, 1993.

SCIFONI, Simone. A construção do patrimônio natural. Tese de doutorado. São Paulo: USP, 2006.

SCIFONI, Simone. A Unesco e o patrimônio da humanidade: valoração no contexto das relações internacionais. In JACOBI, Pedro e FERREIRA, Lúcia da Costa (orgs.). Diálogos em ambiente e sociedade no Brasil. São Paulo: Anppas/ Anablume, 2006, p. 135-153.

SCIFONI, Simoni. Patrimônio mundial: do ideal humanista à utopia de uma nova civilização. GEOUSP - Espaço e Tempo. São Paulo, nº 14, 2003, p. 77- 88.

SILVA, Fernando Fernandes da. As cidades brasileiras e o patrimônio cultural da humanidade. São Paulo: Ed. Pierópolis, Edusp, 2003.

UNESCO. Carpeta de información sobre el patrimonio mundial. Paris, 2005.

ZANIRATO, Silvia Helena e RIBEIRO, Wagner Costa. Conhecimento tradicional e propriedade intelectual nos organismos multilaterais. Ambiente e sociedade. V. 10, n. 1, 2007, p. 39-56.

ZANIRATO, Silvia Helena e RIBEIRO, Wagner Costa. Patrimônio cultural: a percepção da natureza como um bem não renovável. Revista Brasileira de História, n 51. São Paulo, 2006, p. 251-262. 